\section{Overviews on} adverse events in pharmacological interventions

\section{APR 23, 2020}

\section{open ठaccess}

\section{DOI:}

dx.doi.org/10.17504/protocol s.io.bfgqjjvw

\section{Protocol Citation: Elena} Dorando, Thilo Sachse, Tim Mathes, Simone Heß, Petra Thürmann, Sven Schmiedl, Salmaan Kanji, Carole Lunny, Pierre Thabet, Dawid Pieper 2020. Overviews on adverse events in pharmacological interventions. protocols.io https://dx.doi.org/10.17504/p rotocols.io.bfgqjjvw

License: This is an open access protocol distributed under the terms of the Creative Commons Attribution License, which permits unrestricted use, distribution, and reproduction in any medium, provided the original author and source are credited

\section{Protocol status: Working} 03/11/2020: full-text screening finished

Created: Apr 23, 2020

Last Modified: Apr 23, 2020

PROTOCOL integer ID: 36080

\section{(3) Overviews on adverse events in pharmacological interventions}

Elena Dorando ${ }^{1}$, Thilo Sachse ${ }^{1}$, Tim Mathes $^{1}$, Simone Heß ${ }^{1}$, Petra Thürmann ${ }^{2}$, Sven Schmiedl ${ }^{2}$, Salmaan Kanji ${ }^{3}$, Carole Lunny ${ }^{4}$, Pierre Thabet ${ }^{5}$, Dawid Pieper ${ }^{1}$

${ }^{1}$ Institute for Research in Operative Medicine, Witten/Herdecke University, Germany;

2Philipp Klee-Institute of Clinical Pharmacology, Helios University Hospital Wuppertal, Witten/Herdecke University, Germany;

${ }^{3}$ The Ottawa Hospital and Ottawa Hospital Research Institute, Ottawa, Ontario, Canada;

${ }^{4}$ Cochrane Hypertension Group and the Therapeutics Initiative, Department of Anesthesiology, Pharmacology and Therapeutics, University of British Columbia, Vancouver, Canada;

${ }^{5}$ Hôpital Montfort, Ottawa, Ontario, Canada<smiles>C1CCCCCC1</smiles>

\section{Elena Dorando}

Institute for Research in Operative Medicine, Witten/Herdeck...

\section{ABSTRACT}

Please find detailed information on our protocol in the attached PDF file.

\section{ATTACHMENTS}

\section{Protocol_Overviews on adverse events in pharmacological interventions.pdf}


Keywords: Overview,

Adverse event, Adverse

effect, Review, Methods,

Pharmacology,

Pharmacological interventions,

Review on overviews,

Protocol, Reporting

characteristics 